\title{
BMJ Open Dentists' intention to report suspected violence: a cross-sectional study in eight Arab countries
}

\author{
Maha El Tantawi, ${ }^{1}$ Balgis Gaffar, ${ }^{1}$ Arheiam Arheiam, ${ }^{2}$ Wafaa AbdelAziz, ${ }^{3}$ \\ Ola B Al-Batayneh, ${ }^{4}$ Mansur F Alhoti, ${ }^{5}$ Sadeq Al-Maweri, ${ }^{6}$ Mai A Dama, ${ }^{7}$ \\ Mounir Zaghez, ${ }^{8}$ Khalid Saddiq Hassan, ${ }^{9}$ Mona Al-Sane, ${ }^{10}$ Maha AbdelSalam, ${ }^{11}$ \\ Wael Sabbah, ${ }^{12}$ Arwa I Owais, ${ }^{13}$ Fatma Abdelgawad, ${ }^{14}$ \\ Thiyezen Abdullah Aldhelai, ${ }^{15}$ Omar Abd El Sadek El Meligy, ${ }^{3,16}$ Jehan AlHumaid, ${ }^{1}$ \\ Fahad Al-Harbi ${ }^{17}$
}

To cite: El Tantawi M,

Gaffar B, Arheiam A, et al. Dentists' intention to report suspected violence: a crosssectional study in eight Arab countries. BMJ Open 2018;8:e019786. doi:10.1136/ bmjopen-2017-019786

- Prepublication history and additional material for this paper are available online. To view these files, please visit the journal online (http://dx.doi. org/10.1136/bmjopen-2017019786).

Received 25 September 2017 Revised 22 January 2018 Accepted 16 February 2018

Check for updates

For numbered affiliations see end of article.

Correspondence to Professor Maha El Tantawi; maha_tantawy@hotmail.com

\section{ABSTRACT}

Objectives This study assessed dentists' intention in eight Arab countries to report suspected exposure to violence among patients and factors associated with this intention based on the theory of planned behaviour.

Methods A cross-sectional study was conducted in 2016 including a convenience sample of dentists practising in public, private and academic sectors in Algeria, Egypt, Jordan, Kuwait, Libya, Palestine, Saudi Arabia and Yemen. Respondents answered a selfadministered questionnaire collecting information about personal and professional background and perceived ability to identify victims of violence. The questionnaire assessed (on a scale from 1 to 10 using six negative statements) dentists' perception of healthcare system mandated reporting of suspected violence. Six statements were used to assess professional attitude towards reporting suspected violence. Logistic regression was used to assess the association between intention to report suspected violence and perceived ability, perception and attitude adjusting for confounders. Results The response rate was $65.2 \%(n=2936 / 4506)$ from general practitioners $(70.9 \%)$ of mean age $=31$ years with $56.7 \%$ women. Of those, $68.8 \%$ intended to report and $52.2 \%$ considered themselves able to identify violence victims. The mean (SD) negative perception score $=5.3 / 10(2.1)$ and the mean (SD) professional attitude score $=7.5 / 10$ (1.9). In multivariate regression, intention to report was associated with professional attitude (OR 1.08, $95 \% \mathrm{Cl} 1.03$ to 1.14 ), ability to identify violence victims (OR 1.76, 95\% $\mathrm{Cl} 1.45$ to 2.12) and negative perception that reporting is not mandated (OR $0.89,95 \% \mathrm{Cl} 0.85$ to 0.94). Significant differences existed among countries in intention to report.

Conclusion Most dentists intended to report suspected violence and their intention could be explained by the theory of planned behaviour which offers a framework for professional development to support violence victims. Sharing of training resources, policies and guidelines is needed to ensure that practices similar to international guidelines are consistently adopted by dentists across Arab countries.

\section{Strengths and limitations of this study}

- We included dentists from eight Arab countries which increases the geographical representativeness of our findings and fills a knowledge gap about the intended practices of dentists in this region.

- The theory of planned behaviour provides a framework to explain the intention to report and helps in planning professional development activities to better prepare dentists to help their patients.

- Social desirability might have affected our estimates of dentists' intention to report suspected violence.

- Dentists in private practice were under-represented compared with dentists from the public and academic sectors.

\section{INTRODUCTION}

In 2014, WHO issued the first report on the global status of violence prevention. ${ }^{1}$ The report defined interpersonal violence as violence that occurs between family members, intimate partners, friends, acquaintances and strangers, and includes child maltreatment, intimate partner violence and elder abuse in addition to some other forms of violence. The report showed that although the problem is preventable and efforts were already under way to reduce it, much remained to be done. Global statistics ${ }^{1}$ indicate that most cases of violence against children, women and elderly are not reported to authorities or service providers. This emphasises the need of the health sector to have a more active role in documenting and reporting cases of violence.

The Eastern Mediterranean Region which includes Arab countries has one of the highest prevalence of intimate partner violence, the most extensively surveyed of all types of violence, among the six WHO regions $(37 \%)$. Comprehensive information about violence 
against children and the elderly is not available. ${ }^{1}$ Arab countries are more defined by their shared culture than by being a specific race. ${ }^{2}$ Given that what constitutes violence depends on contextual and cultural norms, what would be labelled as violence against women or children in Western countries, may be culturally acceptable or may be considered a private matter in Arab countries. ${ }^{3}$ Because of this, studies related to violence management that were conducted in Western countries may not apply in Arab countries.

Dental care settings are often the primary contact point for violence victims since head and face injuries are sites with common manifestation of physical violence. ${ }^{4}$ Like all healthcare professionals, dentists' main goal is to protect human life and the well-being of their patients ${ }^{5}$ and therefore they can play an important role in identifying and reporting victims of violence. However, we know little about Arab dentists' willingness to report cases of violence. A review of literature showed that there were few studies that were conducted among dentists in Arab countries and that they focused on children abuse in Jordan, ${ }^{67}$ Saudi Arabia ${ }^{89}$ and the United Arab Emirates. ${ }^{10}$ However, none of these studies investigated dentists' intention to report suspicion of violence among adults.

Scientific evidences ${ }^{1112}$ show the importance of studying this topic for the dental community, but there is still the need to assess the willingness of dentists in Arab countries to report suspected violence, considering there are only a few studies performed in this region. Such information helps inform public health policy, laws and future intervention programmes targeting prevention and management of violence. The hypothesis of the study was that dentists' intention to report violence can be explained by the theory of planned behaviour ${ }^{13}$ where dentists would be more willing to report if they perceive that the healthcare system requires them to report (normative beliefs), if they have favourable professional attitude towards reporting (behavioural beliefs) and if they think they are able to identify victims of violence (control beliefs). The aims of this study were to (1) assess the intention of dentists in eight Arab countries to report cases of suspected violence and to (2) identify factors associated with this intention.

\section{METHODS}

Data for this cross-sectional study were collected from April to December 2016 after obtaining the approval of the research ethics committee and in accordance with the guidelines of the Declaration of Helsinki. Dentists were targeted in eight Arab countries: Algeria, Egypt, Jordan, Kuwait, Libya, Palestine, Saudi Arabia and Yemen. To assess the prevalence of intention to report, sample size was calculated (http://www.nss.gov.au/nss/home. nsf/pages/Sample+size+calculator) using the following assumptions: confidence level $=95 \% \mathrm{CI}=5 \%$, total number of dentists in each country ${ }^{14}$ with an estimated percentage of reporting suspected violence $=32 \%{ }^{10}$ The number was increased by $25 \%$ to allow for non-response. The minimum required sample size per country ranged from 300 to 470 dentists.

Participants were selected using convenience sampling including dentists affiliated with professional groups, or from regions where they would be clustered such as capitals and big cities and from different areas in each country to ensure geographical coverage. Because of the war situation in Libya, data collection was restricted only to Eastern Libya. In Algeria, only the city of Annaba was included and the respondents were alumni of Annaba University.

Dentists were invited to participate if they (1) had a bachelor of dentistry or equivalent degree and (2) were practising in one of the eight Arab countries. In the beginning, dentists were included only if they were nationals of the country. Later on, this criterion was dropped due to the presence of a considerable percentage of expats in some countries so that the sample would reflect the profession profile in the participating countries.

Data were collected using a questionnaire that was developed based on previous studies ${ }^{91015}$ (online supplementary file). It consisted of five sections including 20 close-ended questions. The first section sought information about personal background (age in years, gender (male or female) and having children (yes or no)). The second section inquired about professional background including specialisation (general practitioner or specialist/consultant), type of practice (private, public or academic sectors), receiving training (yes or no) and perceived ability to identify victims of violence (yes or no). The third section assessed perception of mandated reporting of suspected violence. Participants were asked to indicate how much they considered each of six statements was true of the place they worked on a scale from not true at all (1) to very true (10). The statements were all negatively phrased and indicated that reporting was not required by law, not enforced, not a rule of the place one worked, not the dentist's job to do, not culturally acceptable and that there was no specific authority to report to. The fourth section assessed respondents' attitude towards reporting violence using six statements to which they were asked to indicate agreement on a scale from completely disagree (1) to completely agree (10). The statements indicated that reporting was the right thing to do, was the dentist's responsibility, that the dentist would always document the manifestations of suspected violence (positive) in addition to statements indicating that the dentist was too busy with patients to report, that the issue of violence was a family's business where nobody should interfere and that it was embarrassing to check about violence (negative). In the fifth section, respondents were asked whether they would report suspected violence to the police, social services agencies/Ministry of Social Affairs, Ministry of Health, non-governmental organisations (NGOs) or others. The questionnaire was pilot tested and culturally adapted in each country.

The questionnaire was preceded by a brief explanation of the study purpose and explained that by responding, the 
dentist indicated consent to join the study. It took about $10 \mathrm{~min}$ to complete and was self-administered, in Arabic and English, as printed and electronic versions. A respondent received the questionnaire by hand or a link to the electronic version was sent to an email list or by WhatsApp message. The investigator issued three reminders over a period of 3 months in case of non-response.

\section{Analysis}

The internal consistency of the statements of perception and attitude was assessed using Cronbach alpha. Overall scores of the two constructs were developed by averaging the items' scores after reverse coding negative attitude statements. Higher perception score thus indicated less (negative) perception so that dentists considered themselves not mandated to report and higher attitude score indicated more positive professional attitude. Separate logistic regression models were developed to assess the association between intention to report suspected violence (dichotomous outcome: yes vs no) and each of (1) perception of mandated reporting (norms) (measured on a scale from 1 to 10), (2) professional attitude towards reporting (measured on a scale from 1 to 10) and (3) perceived ability to identify victims of violence (control) (yes vs no) in addition to personal and professional factors (all were categorical variables except age). Countries were considered to have protective services for children or adults based on the WHO report whether these services were limited, partial or full. ${ }^{1}$ All factors were included in a multivariable model where they were simultaneously adjusted after removing the factors whose estimates showed correlation. All models were adjusted for country of practice. ORs, $95 \%$ CI and $p$ values were calculated for all models and so was the percentage of correctly classified cases for the model including all variables.

\section{RESULTS}

The overall response rate was $65.2 \%$ ranging from $51 \%$ in Palestine to $78 \%$ in Yemen (table 1). Some nationalities

Table 1 Response rate, presence of protective services and intention to report by country

\begin{tabular}{lllr}
\hline Country & Response rate & $\begin{array}{l}\text { Documented } \\
\text { presence of } \\
\text { protective } \\
\text { services }\end{array}$ & $\begin{array}{l}\text { Intention } \\
\text { to report, } \mathbf{n} \\
\text { (\%) }\end{array}$ \\
\hline Algeria & $110 / 175=62.9 \%$ & Yes & $88(80)$ \\
\hline Egypt & $826 / 1271=65 \%$ & Yes & $505(61.1)$ \\
\hline Jordan & $347 / 475=73.1 \%$ & Yes & $271(78.1)$ \\
\hline Kuwait & $449 / 632=71 \%$ & No & $305(67.9)$ \\
\hline Libya & $225 / 389=57.8 \%$ & No & $159(70.7)$ \\
\hline Palestine & $380 / 745=51 \%$ & No & $326(85.8)$ \\
\hline Saudi Arabia & $308 / 446=69.1 \%$ & Yes & $190(61.7)$ \\
\hline Yemen & $291 / 373=78 \%$ & Yes & $175(60.1)$ \\
\hline Total & $2936 / 4506=65.2 \%$ & & $2019(68.8)$ \\
\hline
\end{tabular}

Table 2 Personal and professional background of participants

\begin{tabular}{lr}
\hline & $\mathbf{n}(\%)$ \\
\hline Age & \\
\hline Mean (SD) & $31.0(9.2)$ \\
\hline Gender & $1268(43.3)$ \\
\hline Male & $1659(56.7)$ \\
\hline Female & $1571(53.7)$ \\
\hline Has no children & \\
\hline Specialisation & $2047(70.9)$ \\
\hline General practitioner & $839(29.1)$ \\
\hline Specialist/consultant & $976(34.2)$ \\
\hline Type of practice & $1257(43.9)$ \\
\hline Private sector & $623(21.9)$ \\
\hline Public sector & $565(19.3)$ \\
\hline Academic sector & $1445(52.2)$ \\
\hline Received training & \\
\hline $\begin{array}{l}\text { Perceived ability to identify victims of } \\
\text { violence }\end{array}$ &
\end{tabular}

Presence of protective services for children 1882 (64.1) or adults in country of practice

practised in their own countries and in other countries included in the study (Egyptians $28.1 \%$ vs $29.9 \%$, Jordanians $11.8 \%$ vs $12.6 \%$ and Yemenis $9.9 \%$ vs $10.4 \%)$. The majority of expats were from Asian (5.4\%) or other Arab countries not included in the study $(3.1 \%)$. Protective services for victims of violence were not documented in Kuwait, Libya and Palestine.

The mean (SD) age in years was $31.0(9.2), 56.7 \%$ were women and $53.7 \%$ had no children (table 2). Most respondents were general practitioners $(70.9 \%)$ working in the public $(43.9 \%)$ or private sectors $(34.2 \%)$. Only $19.3 \%$ reported receiving training to manage victims of violence and $52.2 \%$ claimed that they can identify them. Protective services for victims of violence were present in the countries of practice of $64.1 \%$ of the respondents.

The majority of respondents indicated their intention to report suspected violence $(2019,68.8 \%)$, mainly to the police $(933,31.8 \%)$ or social affairs agencies $(842$, $28.7 \%)$ followed by the Ministry of Health (303, 10.3\%) and NGOs $(132,4.5 \%)$. There was a significant difference among countries in the percentage of dentists indicating intention to report ranging from $60.1 \%$ in Yemen to $85.8 \%$ in Palestine $(\mathrm{p}<0.0001$, table 1$)$.

Figure 1 shows that the highest mean negative perception item score was for perceiving that reporting was not enforced (6.5) followed by perceiving that there was no authority to report to (6.2). The internal consistency of perception statements was acceptable (Cronbach alpha $=0.68,95 \%$ CI 0.66 to $0.70, \mathrm{p}<0.0001$ ) and the mean (SD) equals 5.3 (2.1). The highest mean score for statements of attitude towards reporting (figure 2) was 


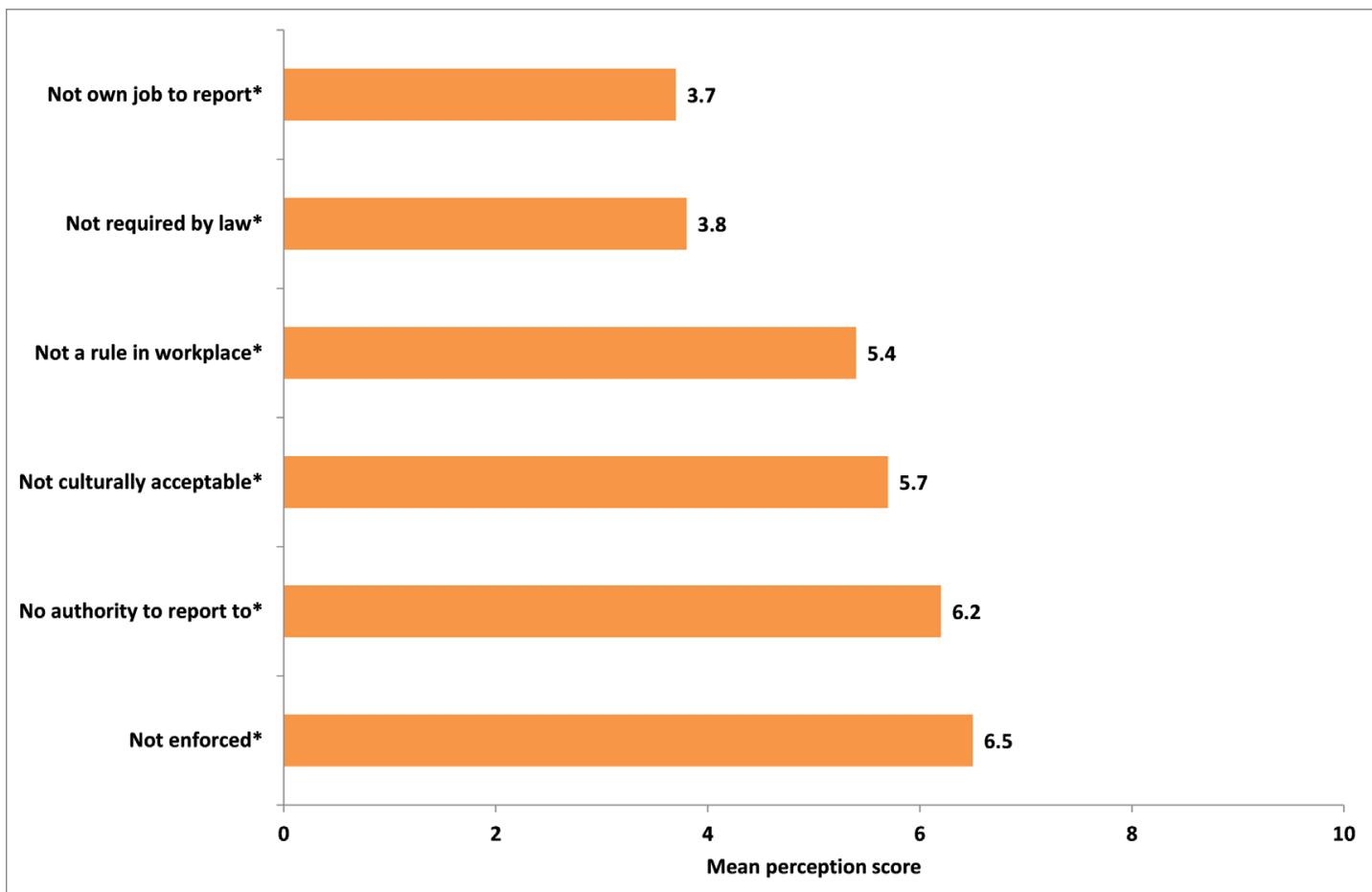

Figure 1 Negative perception of mandated reporting, mean $(S D)=5.3(2.1)$, range=1-10.

for indicating that it was the right thing to do (8.7) and the lowest was for the negative statement indicating that the respondent was too busy treating patients to report (mean=3.2). The internal consistency of the statements was good (Cronbach alpha $=0.72,95 \%$ CI 0.70 to 0.74 , $\mathrm{p}<0.0001)$ and the mean (SD) equals 7.5 (1.9).

Dentists who practised in countries where there were protective services for violence victims had significantly higher negative perception and lower attitude scores than those without such services $(p<0.0001$ and $p<0.02)$. Dentists who reported being able to identify violence victims had significantly lower negative perception and higher attitude scores than those who did not $(\mathrm{p}<0.0001$, table 3). There was a significant moderate negative correlation between perception and professional attitude (Pearson $\mathrm{r}=-0.32, \mathrm{p}<0.0001$ ).

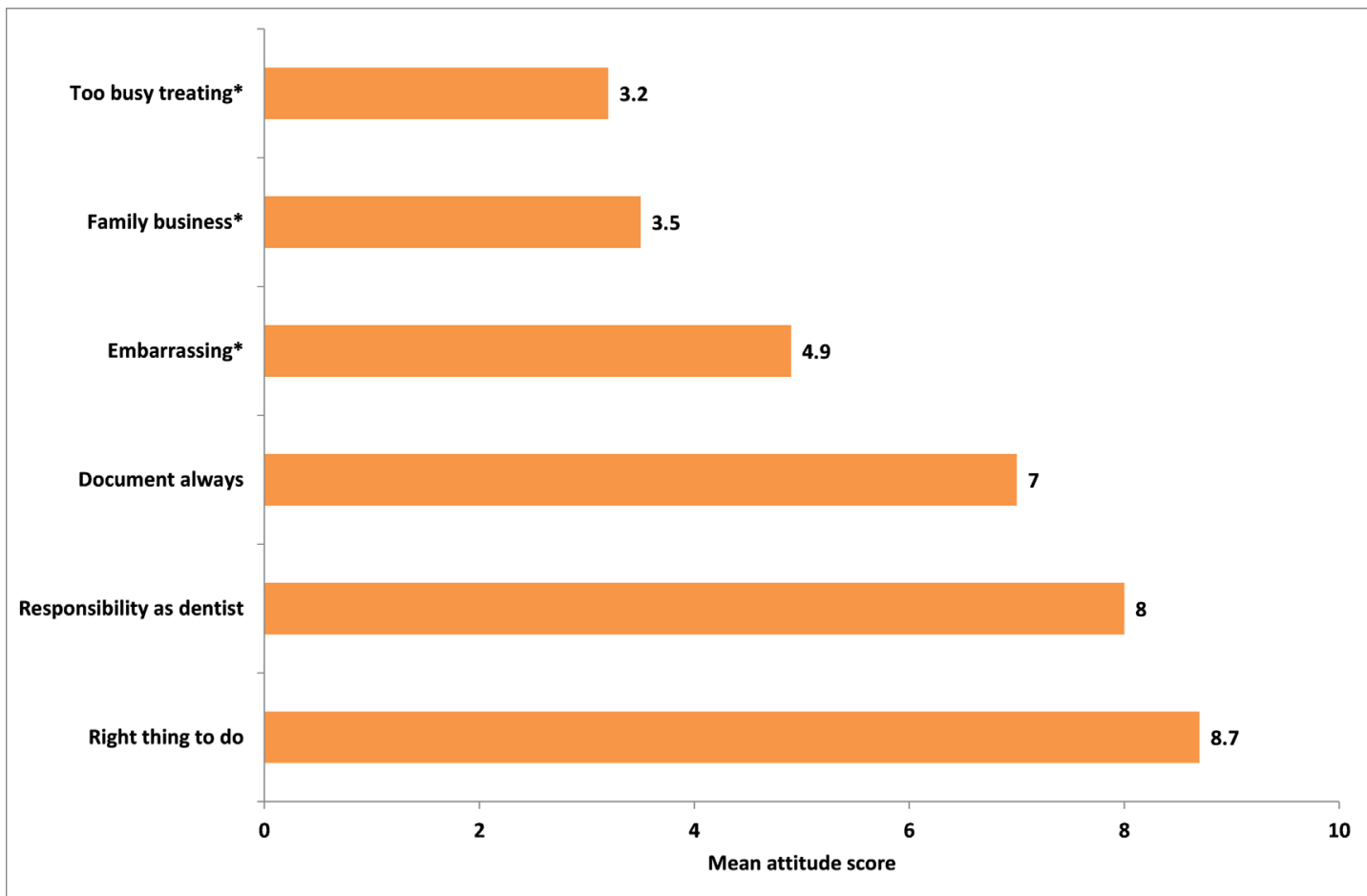

Figure 2 Professional attitude towards reporting, mean (SD)=7.5 (1.9), range=1-10. *Negatively phrased statement. 
Table 3 Association of perception and attitude with presence of protective services and ability to identify victims of violence

\section{Score: mean (SD) P value}

\begin{tabular}{|c|c|c|c|}
\hline & $\begin{array}{l}\text { Protective services in country of } \\
\text { practice }\end{array}$ & $\begin{array}{l}\text { No protective services in country of } \\
\text { practice }\end{array}$ & \\
\hline Negative perception & $5.50(2.13)$ & $4.87(2.11)$ & $<0.0001^{*}$ \\
\hline \multirow[t]{2}{*}{ Positive professional attitude } & $7.41(1.94)$ & $7.59(1.87)$ & $0.02^{*}$ \\
\hline & Able to identify victims of violence & Not able to identify victims of violence & \\
\hline Negative perception & $4.98(2.17)$ & $5.56(2.06)$ & $<0.0001^{*}$ \\
\hline Positive professional attitude & $7.72(1.85)$ & $7.25(1.99)$ & $<0.0001^{*}$ \\
\hline
\end{tabular}

*Statistically significant at $\mathrm{p}<0.05$.

Table 4 shows that attitude, perception and reported ability to identify violence victims were significantly associated $(\mathrm{p}<0.0001)$ with intention to report in the separate models (model 1$)$ in addition to gender $(\mathrm{p}<0.0001)$, age $(\mathrm{p}=0.004)$ and presence of protective services $(\mathrm{p}<0.0001)$. In the multivariable model 2, higher odds of intention to report were significantly associated with higher professional attitude score (OR 1.08, 95\% CI 1.03 to 1.14) and reported ability to identify victims of violence (OR 1.76, 95\% CI 1.45 to 2.12). Lower odds of intended reporting were significantly associated with higher score of negative perception (OR $0.89,95 \%$ CI 0.85 to 0.94 ). In addition, the presence of protective services was associated with significantly lower odds of intention to report (OR 0.34, $95 \%$ CI 0.22 to 0.50 ). The multivariable model 2 correctly classified $71.6 \%$ of dentists based on intention to report suspected violence.

\section{DISCUSSION}

Our results indicated a moderate level of dentists' intention to report suspected violence with significant difference among the eight Arab countries. The findings supported the hypothesis and showed that the theory of planned behaviour ${ }^{13}$ correctly classified most dentists regarding their intention to report suspected violence. A combination of dentist's professional attitude, perceived ability to identify victims of violence and perception of mandatory rules and regulation were associated with intention to report. The presence of protective services in the country of practice was associated with less intention to report.

Most dentists in the present study (68.8\%) indicated they intended to report violence. This finding is similar to those of previous studies in Arab countries such as Jordan ${ }^{6}$ and Saudi Arabia ${ }^{89}$ and Western countries such as Scotland ${ }^{16}$ and Brazil. ${ }^{17}$ However, less intention to report was shown in some studies from Italy, ${ }^{18}$ Brazil $^{19}$ and France. ${ }^{5}$

Even with the most favourable intentions, dentists will not report violence if they cannot identify its signs. In the present study, $52.2 \%$ of the respondents reported being able to identify victims of violence. Previous studies showed differences in dentists' perceived ability to identify victims of violence across countries ${ }^{56818-20}$ which might be attributed to variations in training requirements and opportunities across countries.

Table 4 Factors associated with intention to report suspected violence

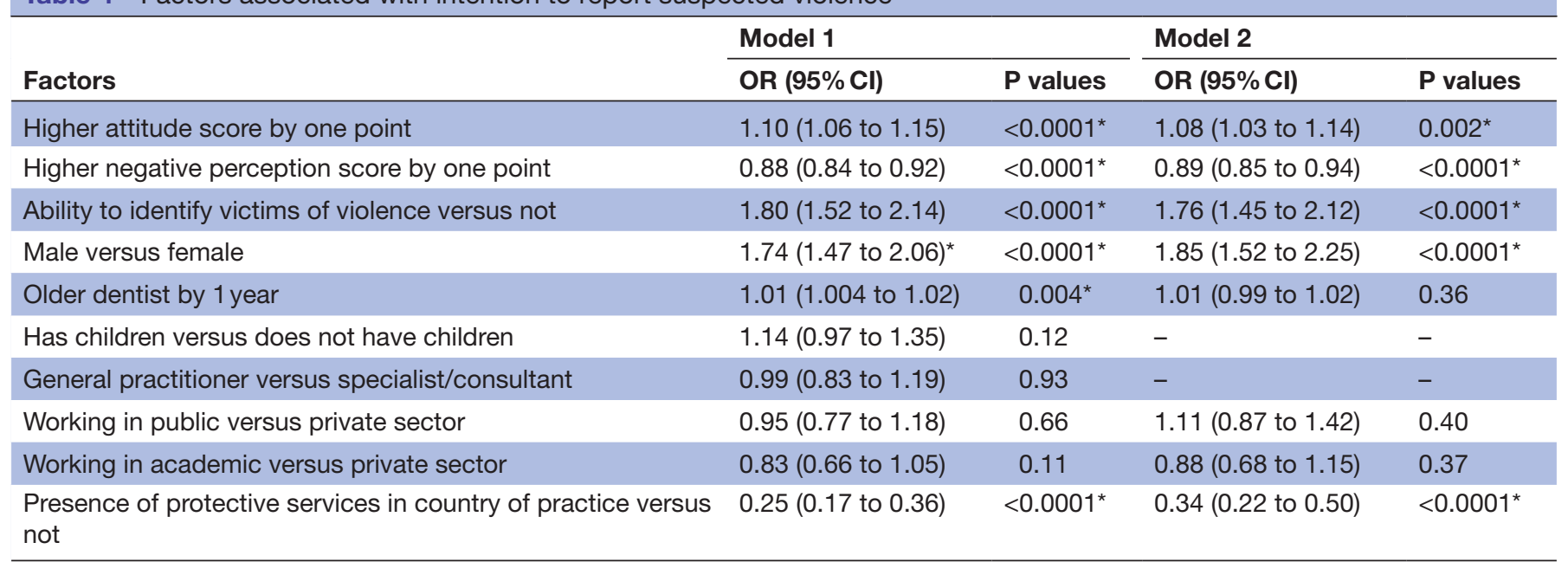

Model 1: includes individual factors adjusted for country of practice.

Model 2: includes all factors adjusted for country of practice.

*Statistically significant at $p<0.05$. Per cent correctly classified by multivariable model: $71.6 \%$. 
Our definition of subjective norms was based on dentists' perception of mandated reporting in the workplace. We used this definition instead of focusing on significant others since the mobility of dentists across countries meant that the values shared by these others may differ from those prevailing in country of practice. The approach we followed was similar to the definition of Ben Natan et $a l^{21}$ where they focused on those who educated nursing students. In the present study, the mean score of negative perception was 5.3/10 indicating that, on average, no clear message was received by dentists from their work place whether or not to report suspected violence. This was more because dentists felt the law was not enforced than their perception that reporting was not mandated (mean=6.5 and 3.8). This agrees with Adair et $a l^{22}$ who concluded that the likelihood of intending to report suspected violence was greater if dentists recognised that they were legally mandated to report. Our finding agrees with previous studies concluding that the presence of laws per se does not necessarily improve the awareness of mandated reporting. For example, Katner and Brown ${ }^{23}$ reported that all 50 American states require dentists to report suspected violence among their patients. Nevertheless, surveys assessing US dentists' knowledge of mandated reporting showed that respondents were not aware of this legal obligation. ${ }^{24}$ The same situation was also reported among Brazilian dentists. ${ }^{19} 20$ Negative perception in the current study was also related to perceiving that there was no authority to report to and the absence of clear rules. Similar perceptions were reported in previous studies addressing child abuse in Arab countries such as Saudi Arabia $^{89}$ and in other countries including India, ${ }^{15}$ USA, ${ }^{25}$ Brazil $^{17}$ and Northern Ireland. ${ }^{26}$ This inadequate knowledge of how or who to report to might be due to the presence of several potential recipients of violence reports ${ }^{10}$ or recent enactment of laws. ${ }^{9}$

In the present study, the presence of protective services was associated with lower odds of intention to report $(\mathrm{OR}=0.34)$, greater negative perception and less positive professional attitude. This might be attributed to dentists not perceiving these services as indicative of real change in social and cultural norms or healthcare system perspective regarding reporting. Alternatively, they might have considered that care of violence victims was shifted to these services so that they would be ethically justified not to report violence. However, studies using qualitative research techniques are needed for further investigation.

In our study, respondents had positive professional attitude towards reporting violence $($ mean $=7.5 / 10)$ which agrees with previous studies from Saudi Arabia concerning reporting suspected child abuse ${ }^{9}$ and domestic violence. ${ }^{27}$ It also agrees with the positive attitude expressed by dentists towards their role in managing child abuse in India, ${ }^{28}$ Scotland, ${ }^{16}$ Jordan, ${ }^{6}$ Brazil $^{20}$ and Greece ${ }^{29}$ as well as domestic violence reporting in Brazil, ${ }^{17}$ India $^{30}$ and France. ${ }^{5}$ Such positive professional attitude-similar to dentists' attitude in other countries—might differ from some negative attitudes and practices in Arab societies that are seen in violence statistics. ${ }^{1}$ The predominance of professional attitude over societal practices agrees with a study showing that cultural differences between Arab and Jewish nursing students in Israel did not affect the intention to screen for domestic violence due to the similarity of their education. ${ }^{21}$ It also agrees with a study from Taiwan, a country with Eastern cultural values, which showed that nurses did not accept the cultural belief that parents can physically discipline their children because these nurses were exposed to mixed cultural influences from the East and West. ${ }^{31}$ The young age of nurses in that study was similar to that of our participants and might explain the similarity between the two studies. However, the professional attitude in our study disagrees with Usta et $a l^{32}$ who reported that Lebanese physicians considered domestic violence a social problem not a medical one and were ready to intervene only when there was actual physical injury. The difference between that study and ours might be because most of the physicians were in private practice and more likely to be worried about the implications on practice income if their local community resented their intervention. Most of the participants in our study, on the other hand, were in the public or academic sectors. Some negative attitudes reported in our study—such as dentists' embarrassment to intervene or considering violence as a family matter-were also reported by $51 \%$ of American dentists in one study, ${ }^{33}$ and cited by $75 \%$ of another group of American dentists as a barrier to reporting. ${ }^{34}$ This shows the global prevalence of the problem that may transcend geographical barriers and cultural backgrounds.

Female dentists in our study were less likely to intend reporting suspected violence. The impact of dentist gender in the issue of suspected violence varied among studies. At the level of knowledge of rules and regulation, female dentists in Saudi Arabia were better than males. ${ }^{9}$ However, actual reporting of suspected violence was more likely among male dentists in Jordan. ${ }^{7}$ Similarly, among Brazilian nurses, of whom $86 \%$ were female, under-reporting of violence was noticed and was attributed to conforming to cultural norms. ${ }^{35}$ Future studies using qualitative research techniques may help elucidate this gender difference and whether it is due to cultural expectations of how females-including dentists-should act or because they are less involved with victims of violence.

In our study, the theory of planned behaviour correctly classified most dentists based on intention to report violence. Previously, the theory predicted the intention of $28 \%$ of Israeli nurses to report child abuse ${ }^{36} 37$ and $32 \%$ of their intention to screen for domestic violence where attitudes and subjective norms were significant predictors (regression coefficients $=0.15$ and 0.05$).{ }^{21}$ Similarly, Feng and $\mathrm{Wu}^{38}$ explained Taiwanese nurses' intention to report child abuse using the same theory. Greater association with the outcome was attributed to professional attitude than subjective norms. The least impact was for perceived control which was attributed to the inadequate instructions of how to report. 
There are some limitations to this study that should be considered. We assessed the intention to report which might differ from actual reporting ${ }^{5}$ and future studies are needed to assess these differences. Self-reporting and social desirability could have affected our estimates of intention to report. We also assessed the intention to report regardless of the type of violence (physical, verbal or otherwise) or victim background (age or gender) and there is a need to investigate how these factors might affect the intention to report. In addition, our estimate of intention to report might have been affected by the under-representation of dentists in private practice compared with those in the public and academic sectors. Our results need to be interpreted with caution due to the convenience sample we used. One of the strengths of our study is the large sample size of 3000 dentists which helps in extrapolating the findings to 59.5 thousand dentists ${ }^{14}$ caring for 213 million individuals in eight Arab countries. ${ }^{39}$ Additionally, the diversity of nationalities and locations helps in reporting on a group of professionals with shared background and allows for wider generalisability.

\section{CONCLUSIONS}

In the present study, dentists' intention to report violence was associated with professional attitudes, perceptions and perceived abilities which were similar to those of dentists in other countries but showed differences by country of practice. Our findings have implications for training to improve the reporting of suspected violence by developing dentists' abilities to identify diagnostic signs, fostering favourable attitude and increasing awareness of already existing rules and regulations. There is a need to develop shared training resources, policies and clear guidelines that allow consistent professional practices and at the same time acknowledge cultural diversity across countries.

\section{Author affiliations}

${ }^{1}$ Department of Preventive Dental Sciences, College of Dentistry, Imam

Abdulrahman Bin Faisal University, Dammam, Saudi Arabia

${ }^{2}$ Department of Community and Preventive Dentistry, Faculty of Dentistry, University of Benghazi, Benghazi, Libya

${ }^{3}$ Department of Pediatric Dentistry and Dental Public Health, Faculty of Dentistry, Alexandria University, Alexandria, Egypt

${ }^{4}$ Department of Preventive Dentistry, Jordan University of Science and Technology, Irbid, Jordan

${ }^{5}$ Benghazi Psychiatric Hospital, Benghazi, Libya

${ }^{6}$ AlFarabi College, Riyadh, Saudi Arabia

${ }^{7}$ Department of Paedodontics and Orthodontics, College of Dentistry, Arab American University of Jenin, Jenin, Palestine

${ }^{8}$ Department of Oral Medicine, Faculty of Medicine, Annaba University (BADJI Mokhtar), Annaba, Algeria

${ }^{9}$ Department of Oral Medicine and Periodontology, Faculty of Dentistry, AIAzhar University, Assiut, Egypt

${ }^{10}$ Department of Developmental and Preventive Sciences, Faculty of Dentistry, Kuwait University, Kuwait City, Kuwait

${ }^{11}$ Department of Biomedical Dental Sciences, College of Dentistry, Imam Abdulrahman Bin Faisal University, Dammam, Saudi Arabia

${ }^{12}$ Department of Population and Patient Health, King's College Hospital, London, UK

${ }^{13}$ Department of Pediatric Dentistry, College of Dentistry, University of lowa, lowa City, lowa, USA
${ }^{14}$ Department of Pediatric Dentistry and Dental Public Health, Faculty of Oral and Dental Medicine, Cairo University, Cairo, Egypt

${ }^{15}$ Department of Orthodontic and Pediatric Dentistry, College of Dentistry, lbb University, lbb, Yemen

${ }^{16}$ Department of Pediatric Dentistry, Faculty of Dentistry, King Abdulaziz University, Jeddah, Saudi Arabia

${ }^{17}$ Department of Substitutive Dental Sciences, College of Dentistry, Imam Abdulrahman Bin Faisal University, Dammam, Saudi Arabia

Contributors MET, MFA and BG developed the study idea and questionnaire. MET developed the study methods. AA, WA, OBA-B, MFA, SA-M, MAD, MZ, KSH MA-S, FA, TAA, OAESEM, JA and FA-H collected data. MET, AA and WS analysed and interpreted the results. MET, AA, WS, AIO, OAESEM, SA-M and WA drafted the manuscripts. All authors read and approved the final manuscript.

Funding This research received no specific grant from any funding agency in the public, commercial or not-for-profit sectors.

Competing interests None declared.

Patient consent Not required.

Ethics approval Research Unit, College of Dentistry, University of Dammam (EA216008).

Provenance and peer review Not commissioned; externally peer reviewed.

Data sharing statement The dataset will be made available from the corresponding author.

Open Access This is an Open Access article distributed in accordance with the Creative Commons Attribution Non Commercial (CC BY-NC 4.0) license, which permits others to distribute, remix, adapt, build upon this work non-commercially, and license their derivative works on different terms, provided the original work is properly cited and the use is non-commercial. See: http://creativecommons.org/ licenses/by-nc/4.0/

(c) Article author(s) (or their employer(s) unless otherwise stated in the text of the article) 2018. All rights reserved. No commercial use is permitted unless otherwise expressly granted.

\section{REFERENCES}

1. World Health Organization. Global status report on violence prevention. $2014 \mathrm{http}: / / \mathrm{www}$. who.int/violence_injury_prevention/ violence/status_report/2014/en/ (Accessed June 10, 2017).

2. Obeidat BY, Shannak RO, Masa'deh RT, et al. Toward better understanding for Arabian culture: Implications based on Hofstede's cultural model. Eur J Soc Sci 2012;28:512-22.

3. Douki S, Nacef F, Belhadj A, et al. Violence against women in Arab and Islamic countries. Arch Womens Ment Health 2003;6:165-71.

4. Coulthard $P$, Warburton AL. The role of the dental team in responding to domestic violence. Br Dent J 2007;203:645-8.

5. Drigeard C, Nicolas E, Hansjacob A, et al. Educational needs in the field of detection of domestic violence and neglect: the opinion of a population of French dentists. Eur J Dent Educ 2012;16:156-65.

6. Owais Al, Qudeimat MA, Qodceih S. Dentists' involvement in identification and reporting of child physical abuse: Jordan as a case study. Int J Paediatr Dent 2009;19:291-6.

7. Sonbol HN, Abu-Ghazaleh S, Rajab LD, et al. Knowledge, educational experiences and attitudes towards child abuse amongst Jordanian dentists. Eur J Dent Educ 2012;16:e158-65.

8. Al-Dabaan R, Newton JT, Asimakopoulou K. Knowledge, attitudes, and experience of dentists living in Saudi Arabia toward child abuse and neglect. Saudi Dent J 2014;26:79-87.

9. Mogaddam M, Kamal I, Merdad L, et al. Knowledge, attitudes, and behaviors of dentists regarding child physical abuse in Jeddah, Saudi Arabia. Child Abuse Negl 2016;54:43-56.

10. Al-Amad SH, Awad MA, Al-Farsi LH, et al. Reporting child abuse cases by dentists working in the United Arab Emirates (UAE). $J$ Forensic Leg Med 2016;40:12-15.

11. Rodrigues J, Lima APB, Nagata JY, et al. Domestic violence against children detected and managed in the routine of dentistry - A systematic review. J Forensic Leg Med 2016;43:34-41.

12. Silva LO, Souza-Silva BN, de Alcântara Rodrigues JL, et al. Identification and management of elder physical abuse in the routine of dentistry - a systematic review. Gerodontology 2017;34:3-12. 
13. Ajzen I. From intentions to actions: A theory of planned behavior. Action control. Berlin, Heidelberg: Springer Berlin Heidelberg, 1985:11-39.

14. World Health Organization. Global Health Observatory data repository. Dentistry personnel - Data by country. Geneva, Switzerland: World Health Organization, 2017.

15. Deshpande A, Macwan C, Poonacha KS, et al. Knowledge and attitude in regards to physical child abuse amongst medical and dental residents of central Gujarat: a cross-sectional survey. J Indian Soc Pedod Prev Dent 2015;33:177-82.

16. Harris CM, Welbury R, Cairns AM. The Scottish dental practitioner's role in managing child abuse and neglect. Br Dent J 2013;214:E24

17. Garbin CA, Rovida TA, Costa AA, et al. [Perceptions and attitudes of public health service dentists in the face of family violence in 24 municipalities in the state of São Paulo, Brazil, 2013-2014]. Epidemiol Serv Saude 2016;25:179-86.

18. Manea S, Favero GA, Stellini E, et al. Dentists' perceptions, attitudes, knowledge, and experience about child abuse and neglect in northeast Italy. J Clin Pediatr Dent 2007;32:19-26.

19. El Sarraf MC, Marego G, Correr GM, et al. Physical child abuse: perception, diagnosis, and management by Southern Brazilian pediatric dentists. Pediatr Dent 2012;34:e72-6.

20. Azevedo MS, Goettems ML, Brito A, et al. Child maltreatment: a survey of dentists in southern Brazil. Braz Oral Res 2012;26:5-11.

21. Ben Natan $M$, Khater M, Ighbariyea R, et al. Readiness of nursing students to screen women for domestic violence. Nurse Educ Today 2016;44:98-102.

22. Adair SM, Yasrebi S, Wray IA, et al. Demographic, educational, and experiential factors associated with dentists' decisions to report hypothetical cases of child maltreatment. Pediatr Dent 1997;19:466-9.

23. Katner DR, Brown CE. Mandatory reporting of oral injuries indicating possible child abuse. J Am Dent Assoc 2012;143:1087-92.

24. Skelton J, Herren C, Cunningham LL, et al. Knowledge, attitudes, practices, and training needs of Kentucky dentists regarding violence against women. Gen Dent 2007;55:581-8.

25. Thomas JE, Straffon L, Inglehart MR. Knowledge and professional experiences concerning child abuse: an analysis of provider and student responses. Pediatr Dent 2006;28:438-44.

26. Lazenbatt A, Freeman R. Recognizing and reporting child physical abuse: a survey of primary healthcare professionals. J Adv Nurs 2006;56:227-36.
27. AIAlyani WS, Alshouibi EN. Dentists awareness and action towards domestic violence patients. A cross-sectional study among dentists in Western Saudi Arabia. Saudi Med J 2017;38:82-8.

28. Malpani S, Arora J, Diwaker G, et al. Child Abuse and Neglect: Do We know enough? A Cross-sectional Study of Knowledge, Attitude, and Behavior of Dentists regarding Child Abuse and Neglect in Pune, India. J Contemp Dent Pract 2017;18:162-9.

29. Laud A, Gizani S, Maragkou S, et al. Child protection training, experience, and personal views of dentists in the prefecture of Attica, Greece. Int J Paediatr Dent 2013;23:64-71.

30. Mythri $\mathrm{H}$, Kashinath KR, Raju AS, et al. Enhancing the dental professional's responsiveness towards domestic violence; A crosssectional study. J Clin Diagnostic Res 2015;9:ZC51-ZC53.

31. Feng JY, Levine M. Factors associated with nurses' intention to report child abuse: a national survey of Taiwanese nurses. Child Abuse Negl 2005;29:783-95.

32. Usta J, Feder G, Antoun J. Attitudes towards domestic violence in Lebanon: a qualitative study of primary care practitioners. $\mathrm{Br} J \mathrm{Gen}$ Pract 2014;64:e313-e320.

33. Love C, Gerbert B, Caspers N, et al. Dentists' attitudes and behaviors regarding domestic violence. The need for an effective response. J Am Dent Assoc 2001;132:85-93.

34. Mascarenhas AK, Deshmukh A, Scott T. New England, USA dental professionals' attitudes and behaviours regarding domestic violence. Br Dent J 2009;206:E5.

35. Rolim AC, Moreira GA, Gondim SM, et al. Factors associated with reporting of abuse against children and adolescents by nurses within Primary Health Care. Rev Lat Am Enfermagem 2014;22:1048-55.

36. Ben Natan M, Ben Ari G, Bader T, et al. Universal screening for domestic violence in a department of obstetrics and gynaecology: a patient and carer perspective. Int Nurs Rev 2012;59:108-14.

37. Ben Natan M, Faour C, Naamhah S, et al. Factors affecting medical and nursing staff reporting of child abuse. Int Nurs Rev 2012;59:331-7.

38. Feng JY, Wu YW. Nurses' intention to report child abuse in Taiwan: a test of the theory of planned behavior. Res Nurs Health 2005;28:337-47.

39. The World Bank. Data for Arab World Population. 2017 http://data. worldbank.org/?locations=1A-DZ (accessed 10 June 2017). 